\title{
MATÍAS MAESTRO, COMERCIANTE Y EXPEDICIONARIO (1789-1792): LOS DIBUJOS DE LA MINA DE PUCAYACO (PERÚ)
}

\author{
MATÍAS MAESTRO, TRADER AND EXPEDITIONARY \\ (1789-1792): THE DRAWINGS OF THE PUCAYACO MINE \\ (PERÚ)
}

\author{
Anthony Holguín Valdez \\ Universidad Nacional Mayor de San Marcos, Lima. Perú \\ ORCID: 0000-0003-0661-3070 \\ anthony.holguin@unmsm.edu.pe
}

\begin{abstract}
El presente estudio aborda la actividad comercial que ejerció el artista español Matías Maestro en Lima entre 1789 y 1792. La relación de Maestro con la Compañía Elizalde-Larreta le permitió concebir una correspondencia importante dentro del circuito mercantil de la ciudad, que le llevó a ser llamado para el proyecto de exploración de las minas de Pucayaco, en Pasco (Perú). Por lo tanto, en este artículo se abordará el estudio de los dos dibujos que realizó para el yacimiento minero y que actualmente se conservan en el Archivo General de Indias.

Palabras claves: Matías Maestro; Compañía Elizalde-Larreta; dibujante; minas de Pucayaco; láminas descriptivas.
\end{abstract}

The present paper addresses the commercial activity that the Spanish artist Matías Maestro exercised in Lima between the years 1789 and 1792. Maestro's relationship with the Elizalde-Larreta Company allowed him to conceive an important correspondence within the city's mercantile circuit, which led him to be called for the exploration project of the Pucayaco mines, in Pasco (Peru). Therefore, the two drawings that he made for the mining site and that are currently conserved in the General Archive of the Indies are analyzed.

Keywords: Matías Maestro; Elizalde-Larreta Company; cartoonist; mines of Pucayaco; descriptive sheets. 


\section{INTRODUCCIÓN}

En la ciudad de Vitoria, actual capital de la comunidad autónoma del País Vasco, situada en el norte de España, nace Matías Maestro un 24 de febrero de 1766. Al día siguiente de su natalicio, fue bautizado en la parroquia de Santa María, siendo sus padres Joseph Maestro e Ignacia Antonia de Alegría Quilchano․ En su juventud, Matías estuvo involucrado en el oficio de contaduría comercial dado que su padre fue dependiente de la casa comercial de los Uriarte en Vitoria. Paralela a esta actividad, adquirió una formación artística en las clases de dibujo académico que recibió en la Escuela de Dibujo de la Sociedad Vascongada de Amigos del País, en la sede del palacio de Escoriaza Esquivel de Vitoria.

Un hecho importante en la educación de Matías Maestro fueron los premios de segunda clase de dibujo en 1780 y el de primera clase en 1781, según se da registro de estos en los extractos de la Sociedad Vascongada de Amigos del País. En la citada Escuela de Dibujo, se impartían las lecciones con modelos clasicistas de esculturas de yeso, pues "el componente escultórico de los antiguos [griegos y romanos] se convierte, como es tradicional en el siglo XVIII, en la base formativa de los estudiantes de artes"2. Además, esto nos aclara que también hubiera tenido oportunidad de copiar dibujos de arquitectura clásica, componente importante para sus proyectos retablísticos de principios del siglo XIX en Lima.

Aún no está del todo claro el objetivo del viaje de Matías Maestro con rumbo a Hispanoamérica. Sin embargo, en nuestra investigación hemos detectado una noticia temprana de Maestro en la ciudad de Lima en el año de 1789. Ahora bien, ¿qué sucedía en el contexto histórico y artístico limeño durante esta fecha y cómo se vincula con la actividad ejercida por Maestro?

En el año 1789, el gremio de pintores de Lima estuvo presente públicamente en los festejos de la exaltación al trono de Carlos IV, acto realizado en la plaza mayor de la ciudad. Este hecho resulta significativo por indicarse la labor corporativa de los pintores en parangón a la de los escritores, estableciendo de esta manera la labor liberal del oficio de pintor. Los trabajos exigidos a los maestros pintores estuvieron determinados por un lapso de ocho días, en el cual debían "pintar tanta copia de Figuras" y escribir "tanta tarja" en los arcos, pirámides y arquitecturas efímeras del evento ${ }^{3}$. En ese sentido, y por toda la obra decorativa de la plaza, el cabildo de Lima asignó el día veinticinco de la celebración pública a los pintores para que pudiesen hacer su fiesta, pues "siempre se ha creído

${ }^{1}$ Los Maestro Alegría Quilchano fueron vecinos de la calle Zapatería y estuvieron dedicados a similares menesteres, siendo el padre José Maestro, que trabajó como contable en la afamada Casa Comercial de Manuel Bartolomé Uriarte. Gónzalez de Zárate, 2007: 36 .

2 Gónzalez de Zárate, 2007: 75.

3 De Terralla y Landa, 1790: s. p. 
necesario mantener al Pueblo en alegría, para moderar las penalidades del trabajo, y la ocupación"4. Incluso se dispuso para los pintores "una hermosa Tienda de Campaña, cubierta con pavellón [sic] Real de Damasco de Seda", ubicado al frente del palacio virreinal, y, en lealtad absoluta, el gremio colocó en su tienda los retratos "del Monarca, y de su inmortal Esposa" 5 .

Entre las obras que se realizaron en la exaltación del nuevo monarca, el gremio de pintores intervino sobre la fachada de la catedral. En esta se colocó el retrato de Carlos IV con las columnas de Hércules, y acompañaba un conjunto de pinturas alegóricas que personificaban a la Prudencia, Justicia, Fortaleza y Templanza con sus respectivos sonetos y jeroglíficos ${ }^{6}$. Sin embargo, las referencias documentales no apuntan a mayor información de los pintores que participaron, solo tenemos nombres como los de Julián Jayo, que realizó pirámides efímeras para el Tribunal de Consulado, y el de Domingo de Urreta, que realizó pinturas de escudos en la fachada del cabildo ${ }^{7}$.

En el conjunto de participantes de la exaltación de Carlos IV, se tienen suficientes datos de los comerciantes convocados para adquirir materiales necesarios para la festividad. Uno de estos es justamente el español Matías Maestro, del que tenemos un recibo de pago firmado el 15 de octubre de 1789, primera referencia documental suya en la capital virreinal. El recibo indica que el vitoriano vendió a don Mariano de Zarate, mayordomo de los propios y arbitrios del cabildo, un total de 22 libras de velas de bujía de cera por el precio de 27 pesos y 4 reales, que sirvieron

${ }^{4}$ De Arrese y Layseca, 1971: 435-436.

${ }^{5}$ De Arrese y Layseca, 1971: 439.

${ }^{6}$ Entre otros edificios que estuvieron "ricamente pintados", se encuentran el cabildo, el palacio virreinal y el portal de Botoneros. No obstante, el capítulo titulado "Vista Adorno, y Colocación de la Fachada de la Santa Iglesia Catedral" describe todo el ornamente distribuido entre pinturas alegóricas, jeroglíficos y sonetos que exaltan la figura del monarca Carlos IV. De Arrese y Layseca, 1971: 222- 238.

${ }^{7}$ Para esta fecha los pintores activos en la ciudad como Pedro Díaz, Teodoro Valverde, José de Urreta, José Joaquín Bermejo, Silvestre Jacobelli y José Mendoza, autodenominados "profesores del arte de la pintura", pudieron ser partícipes de la ceremonia, pues estos lograron aglutinarse como suerte de una corporación tras solicitar a las más altas autoridades del virreinato que se les otorgase la exclusividad con respecto a la valoración de obras artísticas, que en ese momento había sido tomada por los corredores de lonja. Wuffarden, 2006: 122. Sabemos que, en efecto, la solicitud de los artífices llegó hasta las instancias del cabildo de Lima el día 9 de junio de 1789, y que el contenido del informe recibido trataba "Sobre que los corredores de lonja no hagan tasaciones de pinturas, sino los Profesores de este arte". Archivo Histórico de la Municipalidad de Lima (AHML), Libro de Cabildo n $^{\circ}$ 38, f. 91r. En su respuesta del día 16 de junio, el procurador general del cabildo examinó "varios recursos de Pintores" en la actividad de tasar obras de arte, que tuvo como desenlace el nombramiento de "quatro Yndividuos de este arte" para ejercer dicho oficio. AHML, Libro de Cabildo n ${ }^{\circ}$ 38, f. 92r. 
para la función de juramento del monarca Carlos $\mathrm{IV}^{8}$. En efecto, muchas de estas velas sirvieron para iluminar las tarjas que se colocaron en los edificios gubernamentales 9 . Por otra parte, creemos que Matías Maestro se dedicaba en este año al comercio de efectos de Castilla, debido al expediente de licencia de pasajero a Indias de su hermano Clemente Maestro ${ }^{10}$. El documento en mención señala que Matías se dedicó al comercio en Lima: "Por parte de $\mathrm{d}^{\text {n. }}$ Clemente Josef Maestro, natural de la Ciudad de Vitoria en la Provincia de Alva se ha hecho presente, que con motivo de hallarse en Lima su hermano $\mathrm{d}^{\mathrm{n}}$. Matías dedicado al comercio, y con algunos bienes de fortuna, desea tenerle en su compañía, a cuyo fin ha obtenido el previo permiso de su viuda Madre en cuya atención, y en la de hallarse soltero y con los demás requisitos prevenidos para poder pasar a aquellos Reynos, según todo resulta de los documentos que exhura, ha suplicado se le conceda la correspondiente licencia de embarque, expidiéndose la orden conveniente"11.

Luego de constantes solicitudes de viaje, Clemente Maestro recibe el pasaporte y permiso el 19 de noviembre de 1789 en la ciudad de Cádiz. La autorización del viaje se anunció el 20 de noviembre, embarcándose en el navío San Pedro que "se despacha al Callao de Lima”. El joven Clemente emprende el viaje al virreinato del Perú para acompañar a su hermano mayor, que por entonces ya estaba establecido como un próspero comerciante "con algunos bienes de fortuna", por lo cual creemos que estuvo en un cargo dependiente de alguna de las casas comerciales de Lima.

Como ya señalamos, aún desconocemos la fecha de establecimiento de Matías Maestro en Lima. La historiografía señala una fecha más temprana, como enero de 1786, cuando firma un cuaderno de partituras musicales de guitarra ${ }^{12}$. Por otra parte, de comprobarse la hipótesis de González de Zárate sobre la relación de Matías Maestro y el comerciante y político Diego Gardoqui, se podría señalar a este como el responsable de traer a Lima al joven vitoriano ${ }^{13}$. Sin embargo, la presencia de ambos personajes, tanto Gardoqui como Maestro, no se constata en un oficio del Real Tribunal de Consulado de Lima, fechado el 30 de marzo de 1787, en el que se da cuenta de una lista de comerciantes activos de la ciudad $^{14}$.

${ }^{8}$ AHML, Superior Gobierno-Virreyes, caja N. 1, doc. 002, 1789, f. 47r.

9 Por ejemplo, en el adorno de la fachada del palacio virreinal se indicó que "cada Tarja llevará Luces necesarias para su lucimiento". De Terralla y Landa 1790: s. p.

${ }^{10}$ Los efectos de Castilla consistían en una variedad de bienes comerciales que incluían productos agrícolas, materias primas y manufacturas.

11 Archivo General de Indias (AGI), Contratación, 5533, N. 2, R. 87.

12 Santa Cruz, 2001: 20.

13 Gónzalez de Zárate señala que Matías Maestro tiene vínculos con la casa comercial Uriarte a partir de 1781, en donde trabajó en funciones contables para la citada compañía vitoriana. Gónzalez de Zárate, 2007: 88.

${ }^{14}$ El documento titulado "Representación hecha al R'. Tral. por Real Comercio en $\mathrm{q}^{\text {to }}$. al origen y atraso que padece y pide informar a S.M." da cuenta de un extenso pedido 


\section{ASOCIACIONES COMERCIALES: ELIZALDE, LARRETA Y COMPAÑÍA}

Como anota la historiadora Cristina Mazzeo, el comercio colonial sufrió varios cambios y transformaciones, en especial a partir de la segunda mitad del siglo XVIII, los cuales desarticularon el monopolio de los grandes centros mercantiles coloniales, especialmente Lima y México. Esto produjo un acomodamiento de sus élites comerciales, que "buscaron nuevas alianzas para asimilarse a los nuevos juegos del intercambio" ". En efecto, luego de establecerse el Reglamento de Libre Comercio en $1778^{16}$, lejos de significar la decadencia del puerto del Callao y de la comunidad de comerciantes establecidos en la capital del Perú, fue una etapa en la cual Lima se reafirmó como centro distribuidor del comercio del Pacífico sur. La liberalización comercial fue un reto y una oportunidad para "los cuales estos comerciantes - por lo menos un sector de estos muy fuertemente consolidadoestaban preparados y dispuestos a asumirlos con todas sus consecuencias" ${ }^{17}$. El conjunto de los comerciantes que representaron estas redes de asociaciones mercantiles de Lima fueron los Elizalde, originarios de Navarra, y que pasaron a dominar a través de sólidas redes familiares y de paisanaje el dinámico comercio del Perú en el último tercio del siglo XVIII.

Es justamente con la compañía manejada por los Elizalde que, a partir de enero de 1787, como señala la historiadora Deolinda Villa, aparece en los protocolos la razón social Elizalde, Larreta y Cía. Dicha empresa se había creado como compañía general de negocios, en la que "se asociaron Antonio y José Matías de Elizalde, Matías de Larreta y Cristóbal de Azpilcueta, todos comerciantes navarros"18. Según Villa, la asociación nació de la necesidad de los Elizalde de racionalizar la administración de sus negocios, que estaban adquiriendo volúmenes cada vez más importantes. Por ello, se exigió contar con una más amplia organización, a través de la cual se distribuyeran las engrosadas responsabilidades; así, "de este modo las disposiciones de la sociedad establecieron que tendría una duración de seis años, que empezó a correr desde el 1 de enero de 1787 "19. La dirección general de los negocios quedaba en manos de Larreta, luego que Antonio

al virrey sobre el deplorable estado del comercio por la abundancia de efectos y la falta de fondos de dinero. Archivo General de la Nación (AGN), TC-GO 2, leg. 5, doc. 115, 1787, ff. 1-9.

15 Mazzeo, 1997: XI.

${ }^{16}$ Los efectos del Reglamento del Libre Comercio se hicieron sentir a partir del año 1784 con el restablecimiento del tráfico, una vez finalizada la guerra con Inglaterra. Villa, 1997: 145.

17 Villa, 1997: 133.

18 Villa, 1997: 149.

19 Los Elizalde y su compañía participaron activamente en el reforzamiento de Lima y el puerto del Callao como ejes de una triangulación que unía las producciones del norte 
Elizalde fue elegido alcalde de Lima en 1787. De esta manera, la compañía debió disolverse en 1792, tiempo estipulado por los socios, y que de hecho se puede corroborar por la escritura notarial de cesión de negocios entre Matías Maestro y Matías de Larreta, cuyo vínculo con la compañía puede esclarecer las asociaciones comerciales del vitoriano a su llega a Lima. Pero, ¿cómo comprobamos la presencia de Matías Maestro en la compañía que dirigió Larreta? La respuesta se encuentra en los autos seguidos sobre las elecciones del priorato del Tribunal del Consulado de Lima, realizadas a fines de 1790. En una agitada sesión de elección se indicó lo siguiente: "la intima familiaridad, amistad y aun commensalidad con don José Robledo principal agente en las ideas contrarias. El referido don José va de acuerdo con don Blas Ignacio de Telleria pariente o deudo de la muger de dicho señor juez y ambos íntimos parciales de don Antonio de Elizalde a quien proclaman notoriamente de prior general [...]. Igualmente se haya implicado dicho señor juez con la dependencia e inmediación de don Matías Maestro compañero en una tienda de mercaderías con don Matías de Larreta, que lo es general en todos los negocios y comercios del referido don Antonio Elizalde"20.

Se menciona que los comerciantes capitalinos José Robledo y Blas Ignacio de Tellería fueron nombrados como parte de la matrícula de electores, decisivos para la elección del nuevo prior, y, en tanto, fueron acusados por el grupo rival conformado por el conde de San Isidro y Benito Sarroa, prior y cónsul en orden, dispuestos a retener el control del Tribunal del Consulado, quienes veían en dichos comerciantes una actuación a favor de su contrincante don Antonio de Elizalde, que postulaba al cargo de prior. Del mismo modo es acusado el juez de alzadas del Tribunal, Nicolás Vélez de Guevara, indicado como dependiente de Matías Maestro.

Así mismo se alega que Maestro es compañero de tienda de mercaderías de Matías de Larreta, que por entonces manejaba la compañía de los Elizalde. Esto no indica que el vitoriano necesariamente exportara mercaderías hacia la metrópoli sino, más bien, que importaba efectos de Castilla y los distribuía en Lima, pues, como sabemos, uno de estos productos fueron las velas de bujía en la ya citada ceremonia de exaltación de Carlos IV. Además, la relación comercial entre Maestro y Larreta finalizó el 10 de diciembre de 1792, fecha que coincide con la disolución de la compañía de Elizalde y Larreta. En dicha escritura protocolar, Matías otorgaba su poder cumplido y "cesción bastante irrevocable, qual por derecho se requiere y es necesario a d ${ }^{n}$. Matías de la Reta [sic]"21. Por lo tanto, la proximidad entre ambos comerciantes está documentada por lo menos desde

de Chile (cobre), el Alto Perú (estaño), Guayaquil y Piura (cacao y cascarilla) con los mercados metropolitanos. Villa, 1997: 149-150.

20 Parrón, 1995: 41.

${ }^{21}$ AGN, Protocolos Notariales, escribano Joseph de Aizcorbe, protocolo 32, 1792, f. $462 \mathrm{v}$. 
1790, y confirma que Maestro formó parte de la circulación de bienes y negocios que cubría el extenso comercio de la compañía Elizalde y Larreta. El vitoriano fue uno de los agentes comerciales llegados a Lima con la finalidad de conectar la empresa con los flujos de mercancías traídas desde España.

\section{COMERCIANTES DE MINERALES Y LOS DIBUJOS DE PUCAYACO}

Las relaciones mercantiles de Matías Maestro y Larreta y Compañía determinaron que, en el núcleo del gremio de comerciantes, conociese a dos personajes dedicados al rubro de la minería. Este hecho fue determinante para la elección de Maestro como el encargado de registrar en dibujos la expedición de reconocimiento de las minas de Pucayaco, en Cerro de Pasco. En esta actividad como ilustrador, elaboró una serie de dibujos sobre la mina de los que actualmente se conservan dos láminas de una colección extraviada en el Archivo General de Indias de Sevilla.

El primer contacto de Maestro fue con el comerciante don Juan Manuel Guiror, destacado como distribuidor de manufacturas españolas en Lauricocha. En una escritura notarial de obligación, fechada en agosto de 1791, Matías Maestro otorga a Guiror varios efectos de Castilla; además, este último declaraba estar "de partida para el mineral de Pasco", lo que, en efecto, demuestra la actividad de este personaje en el comercio de una de las regiones de mayor producción de minerales en el siglo XVIII, pues se sabe que las minas de Cerro de Pasco era el principal centro minero que abastecía a Lima ${ }^{22}$. Asimismo, la obligación indica que Guiror debió pagar la cantidad de 1.220 pesos y 6 reales por el importe de varios efectos de Castilla ${ }^{23}$. La obligación notarial con Maestro se cancela en octubre de 1793 .

Tenemos registro de un segundo comerciante de nombre Juan de Echevarría y Bengoechea, de origen vasco ${ }^{24}$, que llegó a ser teniente general de la provincia de Huamalies y tesorero de la Aduana, así como director del Tribunal de Minería, cargo que le conllevó tener contacto directo con un núcleo importante de comerciantes españoles y limeños. Entre estos personajes se ubica Matías Maestro,

${ }_{22}$ El auge de la extracción mineral en Cerro de Pasco se truncaría a principios del XIX, como señala el historiador Timothy Anna. Después de 1812, la producción de plata del Perú colapsó finalmente como resultado de la inundación de las minas de Cerro de Pasco -que habían producido hasta el 40 por ciento de la plata peruana- y de las conmociones causadas por la guerra de independencia. Anna, 2003: 32.

${ }_{23}$ AGN, Protocolos Notariales, escribano Joseph Aizcorbe, protocolo 31, 1791, f. 264.

${ }^{24}$ Nació en Aulestia, en el señorío de Vizcaya, y estaba casado con doña María de Santiago Ulloa, natural de Valparaíso. De Mendiburu, 1878: 25. 
quien le concede una obligación en agosto de $1791^{25}$, por la que debía realizar cobros, representaciones judiciales y otras acciones, un característico poder general con el que se iniciaba una asociación mercantil permanente. Por otra parte, Echevarría, dentro de sus funciones en el Tribunal, conoció a Miguel de Iriarte, español y comerciante de minerales, elegido diputado de la las minas de San Mateo de Huarochiri, en febrero de $1788^{26}$. La elección de Iriarte en el cargo de diputado fue por orden directa del director del Tribunal, quien le favoreció el puesto y, más adelante, apoyó en sus intereses de explorar nuevas vetas de azogue en la sierra peruana ${ }^{27}$.

Entonces, ¿cuál fue el contexto en el que se originan los dibujos de las minas de Pucayaco de Matías Maestro? Como ya señalamos, Matías Maestro fue dependiente de la compañía Elizalde y Larreta. Además, la empresa aglutinó otros comerciantes dedicados a la distribución comercial de minerales y uno de estos fue el comerciante español Miguel de Iriarte, personaje que estará involucrado en la exploración de las minas de Pucayaco. Este comerciante originario del valle del Baztán, en Navarra ${ }^{28}$, señala en su testamento de 1810 un poder otorgado a sus acreedores en el que se refieren los negocios que tuvo en el comercio minero. Así, en la escritura notarial, se cita como testigos a Antonio Elizalde, Gaspar Rico, José Miguel Altola, Blas Ignacio de Tellería y José Ugarte ${ }^{29}$. De este núcleo de personajes, son Elizalde y Tellería quienes entablaron vínculos mercantiles con Matías Maestro. Por lo tanto, la asociación y triángulo comercial de la compañía Elizalde, Miguel de Iriarte y Matías Maestro puede fecharse entre 1790 y 1791, años clave, pues Miguel de Iriarte ya disponía del centro minero de Pucayaco en Huarochiri, un yacimiento de extracción de mercurio, un producto importante para el procesamiento de la plata que era obtenida de Cerro de Pasco.

Conocemos por un expediente del Tribunal de Minería, fechado el 31 de marzo de 1788, que Miguel de Iriarte presenta al virrey Teodoro de Croix una solicitud para que se habilite el trabajo de la mina de Pucayaco. El documento indica lo siguiente: "Dirixo [sic] a V.S. el adjunto recurso/ original que me ha hecho Dn./ Miguel de Yriarte, Descubridor/ de la Mina de Azogue nombrada/ Pucayaco Partido de Guarochiri,/ sobre la necesidad de auxilios para su/ fomento; y

${ }^{25}$ La carta de poder señala a Juan de Echevarría residente en la Villa de Pasco. AGN, Protocolos Notariales, escribano Joseph de Aizcorbe, protocolo 31, 1791, f. 255r.

${ }^{26}$ AGN, TM-AD 1, leg. 2, exp. 40, 1788, ff. 1-5.

${ }^{27}$ En enero de 1789, Juan de Echevarría y otros funcionarios del Tribunal de Minería solicitaban la aprobación del acta de elección de diputados sustitutos de Huallamarca, acto que favoreció a comerciantes limeños que se dedicaban a la distribución mercantil de minerales. AGN, TM-AD 1, leg. 2, doc. 54, 1789, ff. 1-4.

28 AGN, Protocolos notariales, escribano José de Cárdenas, protocolo 133, 1810, f. 20v.

${ }^{29}$ El poder es otorgado el 16 de abril de 1810. AGN, Protocolos notariales, escribano José de Cárdenas, protocolo 133, 1810, f. 51r. 
a fin de que en el supuesto/ de hallarse la Real Hacienda/ tan agotada, y sin fondos para/ atender las precisas urgencias,/ y necesidades del estado, me informe/ si del real marco; ó de otros fondos/ pertenecientes a ese Tribunal/ podrían franquearse algunas cantidades/ a dho. Yriarte para una/ empresa tan útil, y benéfica al cuerpo/ de Minería, como en la activa labor/ de su Mina de Azogue" ${ }^{30}$.

El oficio, recibido en abril por el Superior Gobierno, siendo el virrey Teodoro de Croix, ordena al Real Tribunal de Minería que habilite una inversión monetaria necesaria a Miguel de Iriarte para la exploración de la mina de azogue ${ }^{31}$. El expediente indica a Iriarte como "minero", pues este no solo se dedicó a este comercio, sino que también fue diputado del Tribunal de Minería en el pueblo de San Mateo de Huarochiri. Así mismo el virrey, en respuesta, autoriza en mayo la entrega de fondos a Iriarte para el desarrollo de la mina de Pucayaco ${ }^{32}$. Por lo tanto, podemos precisar que las labores en esta mina debieron iniciarse a mediados de 1788, fecha en la cual Iriarte tuvo el presupuesto y empezó a instalar los campamentos, herramientas, obreros y redes de transporte, así como la distribución y venta del mercurio. En este contexto se sitúa la participación de Matías Maestro, quien es convocado por el director del Tribunal de Minería, Juan de Echevarría, socio de negocios mercantiles con el vitoriano, y de cuya labor debía ser participe como dibujante expedicionario en Huarochiri, una labor que ejerció en los primeros meses de 1789.

En efecto, la labor del dibujante expedicionario consistía en realizar una copia al "natural" del objeto a registrar. Esto comprometía al artífice a tener contacto directo con el modelo para lograr una mayor precisión, verismo y descripción del objeto; así, por ejemplo, en una carta dirigida al virrey del Perú Francisco Gil fechada en marzo de 1794, el botánico Juan Tafalla y el dibujante Francisco Pulgar indican la técnica que emplean en esta labor de registro: "las instrucciones del método que debemos observar en nuestros viajes excursiones y formación de los dibuxos, y descripciones, para el mejor éxito de nuestra comisión, las que observaremos con la mayor exactitud, y zelo a fin de desempeñar nuestro cargo" ${ }^{\prime 3}$. De aquí se deriva que el método empleado en el dibujo científico comprende realizar con "la mayor exactitud" la descripción del objeto (plantas, animales, humanos o paisaje); además, esto iba acompañado de un informe escrito que se asemejaba a una ficha de catalogación.

La primera referencia de los dibujos de las minas de Pucayaco, realizados por Matías Maestro, se sitúa en 1906, en la publicación de la Relación descriptiva de los mapas, planos, etc. del Virreinato del Perú (Perú y Chile), a cargo del entonces

${ }^{30}$ El expediente es recibido el 1 de abril de 1788 para su posterior traslado al Superior Gobierno. AGN, TM-AD 3, leg. 18, doc. 57, f. 1r-v.

${ }^{31}$ AGN, TM-AD 3, leg. 28, exp. 60, 1788, ff. 1-4.

32 AGN, TM-GO 1, leg. 27, exp. 49, 1788, ff. 1-2.

${ }^{33}$ AGN, GO-CO 2, leg. 207, exp. 1987, 1794, f. 1r. 
jefe del Archivo General de Indias de Sevilla Pedro Torres Lanzas ${ }^{34}$. Sin embargo, esta edición no incluye las fotografías de las láminas ${ }^{35}$. Los dos dibujos están elaborados en base a la técnica de tinta aguada sobre un soporte de papel verjurado y ambos llevan la firma "Matías Maestro, fecit" (Matías Maestro lo hizo), ubicadas en la zona inferior izquierda de cada dibujo. El historiador del arte Rafael Ramos Sosa apunta que los dos dibujos de Maestro "formaban parte de un manuscrito de más de 300 folios titulado Instrucciones sobre el arte de las minas, con otros dibujos y planos", pero el autor no cita la fuente sobre aquel expediente ${ }^{36}$. Lo cierto es que el conjunto de láminas debió formar parte de un grupo superior a la treintena, debido a que uno de los dibujos lleva escrito en el dorso el número "33". No obstante, con estas láminas elaboradas por Maestro podremos aproximarnos al análisis compositivo y determinar el breve paso que tuvo el vitoriano en el dibujo científico, propio de artistas expedicionarios.

La primera lámina tiene por título "VISTA DE LA MINA/ DE/ PUCAYACO/ TOMADA 230 VARAS AL NO. DEL POZO S. CARLOS", llevando al dorso escrito el número 26 (Figura 1). El dibujo, como puede verse, está delimitado por un marco rectangular y una leyenda narrativa en su parte inferior, que da cuenta en una lista enumerada de la descripción del territorio. La firma se ubica en el ángulo inferior izquierdo, donde se lee: "Matías Maestro, fecit". El primer plano se inicia desde el margen izquierdo hasta la parte central de la lámina. En ella está dibujada parte de un monte escarpado retratado con finas pinceladas de tinta sepia y la textura del pasto menudo del suelo, que convergen a las orillas del río "Pucayaco". El segundo plano está definido por un amplio terreno deshabitado donde se ubica la galería de la mina y próximo a este se encuentra un arriero y sus auquénidos. Por el lado opuesto, en el margen derecho, se sitúan

${ }^{34}$ Existe una reimpresión realizada por el Ministerio de Cultura de España en 1985 con el título Archivo General de Indias. Catálogo de mapas y planos. Virreinato del Perú (Perú y Chile). Esta edición incluye imágenes de los mapas o planos. Asimismo, queremos mencionar otras ediciones de catálogos que realizó Torres: los volúmenes de México (1900), Guatemala (1903) y, por último, Panamá, Santa Fe y Quito (1904).

${ }^{35}$ En 1906, el primer dibujo, "Vista de la mina de Pucayaco, tomada 230 varas al N.O. del Pozo de San Carlos", tuvo como ubicación: estante 147, cajón I, legajo 8 (1). El segundo, titulado "Vista de la Hacienda de Pucayaco, tomada 50 varas al N.N.E. de Casa principal", tuvo la referencia de inventario: estante 147, cajón 1, legajo 8 (2). Torres, 1906: 7-8. Los dibujos hoy se encuentran depositados en la sección de Mapas y Planos del Archivo General de Indias y tienen como unidad de procedencia "AGI, INDIFERENTE, 1773". La "Vista de la Hacienda de Pucayaco, tomada 50 varas al N. N. E. de la Casa principal” presenta el código de referencia "ES.41091.AGI//MP-PERU_CHILE,3", y la "Vista de la mina de Pucayaco, tomada 230 varas al N. O. del Pozo de San Carlos" tiene por código "ES.41091.AGI//MP-PERU_CHILE,2". Lamentablemente, en la sección de Mapas y Planos no se encontró mayor información que nos ayude a contextualizar las láminas.

${ }^{36}$ Ramos Sosa, 2004: nota 119. 
los "Ranchos de los Operarios", un conjunto de viviendas con techos de cuatro vertientes de aspecto cónico que rodean un gran crucifijo. La composición concluye con la presencia del cerro Huachuacancha, un terreno escarpado y de cima llana donde se delinea el "Arroyo que baña los rancho". Por último, transcribimos el listado de la leyenda del dibujo: "1. Cerro de Huachuacancha; 2. Galería ó Cañón de $\mathrm{S}^{\mathrm{n}}$. Migl.; 3 . Boca de $\mathrm{S}^{\text {to }}$. Domingo; 4. Pozo de $\mathrm{S}^{\mathrm{n}}$. Carlos; 5. Ranchos de los Operarios; 6. Arroyo que baña los ranchos; 7. Camino de la Hacienda; 8. Río Pucayaco".

En cuanto a la segunda lámina, tiene por título "VISTA DE LA HACIENDA/ DE/ PUCAYACO/ TOMADA 50 VARAS AL N.N. E. DE LA CASA PRINCIPAL" (Figura 2). Al dorso se ubica el número 33. El dibujo está definido por su marco interior y la correspondiente leyenda narrativa en la parte baja. El primer plano circunda un amplio terreno agreste, desde cuyo margen derecho se observa un acantilado y la cascada del río Pariacancha; este sector se comunica con los pastizales y cerros cubiertos de vegetación. En el mismo plano, se observa la casa principal o centro de operaciones de Miguel Iriarte, donde además se ubican los hornos para la extracción de "Azogue". Todo este conjunto de arquitectura rústica de material pétreo con cubiertas a dos aguas enriquece el dibujo a detalle del artista. El tercer plano circunda un cerro rocoso de cima empinada cubierta de escarpados, sugiriendo con líneas sinuosas los dos caminos que conducen hacia la mina y al pueblo de Pucará. También el dibujo procura narrar con la mayor precisión el listado de la leyenda: "1. Casa principal; 2. Hornos pa la extracción del Azogue; 3. Almacén pa el ychú o paxa; 4. Camino de la Mina; 5. Río Pucayaco y su cascada; 6. Camino a Pucará; 7. Río Pariacancha”.

Los dibujos de Matías Maestro se componen de una regla de tercios horizontales, donde el paisaje se ubica en los dos inferiores, y delimita al cielo como recurso de equilibrio del espacio. Además el artista rehúsa sobrecargar el degradado de la tinta sepia, y demuestra sus dotes en el dibujo lineal, el detallismo y el juego de sombras tanto del propio paisaje como del conjunto de viviendas de minería, los escarpados de los cerros, la corriente del río, los pastizales y el grupo de auquénidos. En cuanto el cielo, utiliza un difuminado de la tinta desde la zona superior hacia abajo.

\section{CONCLUSIONES}

La actividad del dibujante en las exploraciones científicas durante el periodo virreinal peruano del siglo XVIII fue fundamental para el desarrollo de la cultura visual y el registro de los territorios, paisajes, pueblos, costumbres, vegetación y fauna. Los dibujos de Matías Maestro se ubican dentro del conjunto de registros de los nuevos espacios de extracción mineral, así como suponen una aportación a la iconografía del territorio de Pucayaco, en Pasco, sierra central del Perú. Además, creemos que estos dibujos pueden fecharse a principios de 1789, pues un año 
antes Miguel de Iriarte resolvía los trámites para la exploración de las minas de Pucayaco, y a finales del referido periodo ya había adquirido la inversión otorgada por el virrey del Perú. Por otra parte, Maestro está presente en Lima en el mes de octubre de 1789 y su permanencia ininterrumpida en la ciudad está documentada hasta 1793 , cuando se retira de la actividad comercial y adquiere los hábitos clericales. Por último, las conclusiones que se han podido extraer a la luz de las fuentes primarias corroboran la actividad comercial aún poco estudiada de Matías Maestro y los dibujos de las minas de Pucayaco evidencian su paso por este oficio.

Fecha de recepción: 30 de octubre de 2019

Fecha de aceptación: 13 de abril de 2020

\section{BIBLIOGRAFÍA}

Anna, Timothy (2003): La caída del gobierno español en el Perú. El dilema de la independencia. Lima: Instituto de Estudios Peruanos.

De Arrese y Layseca, Francisco ([1790] 1971): "Descripción que por la feliz exaltación del señor Don Carlos IV". En: Colección Documental de la Independencia del Perú. La Universidad, Libro XIV de Claustros, tomo XIX, volumen 2. Lima: Comisión Nacional del Sesquicentenario de la Independencia del Perú, pp. 401-474.

De Mendiburu, Manuel (1876): Diccionario histórico-biográfico del Perú. Lima: Imprenta Bolognesi, tomo III.

De Terralla y Landa, Estevan (1790): El sol en el medio día: año feliz, y júbilo particular con que la nación indica de esta muy noble Ciudad de Lima solemnizó la exaltación al trono de Ntro. Augustísimo Monarca el señor Don Carlos IV. Lima: Casa Real de Niños Expósitos.

González de Zárate, Jesús (2007): Matías José Maestro (1766-1835), arquitecto, escultor, pintor, músico, escritor. Vitoria: Diputación Foral de Álava, Departamento de Euskera, Cultura y Deportes.

Mazzeo, Cristina (1999): "Introducción”. En: Los comerciantes limeños a fines del siglo XVIII. Capacidad y cohesión de una elite. 1750-1825. Lima: Pontificia Universidad Católica del Perú, pp. XI-XVI.

Parrón, Carmen (1995): De las reformas borbónicas a la República: el Consulado y el comercio marítimo de Lima, 1778-1821. Murcia: Imprenta de la Academia General del Aire.

Ramos Sosa, Rafael (2004): "La grandeza de lo que hay dentro: escultura y artes de la madera”. En: Lohmann, Guillermo (ed.): La Basílica Catedral de Lima. Lima: Banco de Crédito, pp. 113-169.

Santa Cruz, Octavio (2001): Matías Maestro guitarrista: el cuaderno de guitarra de 1786. Lima: Biblioteca Nacional del Perú. 
Torres, Pedro (1909): Relación descriptiva de los mapas, planos, etc. del virreinato del Perú (Perú y Chile) existentes en el Archivo General de Indias (Sevilla). Barcelona: Imp. Henrich y $\mathrm{C}^{\mathrm{a}}$.

Villa, Deolinda (1999): "Liderazgo poder: la elite comercial limeña. Entre el comercio libre y la guerra de la independencia (el caso de Antonio de Elizalde)". En: Mazzeo, Cristina (ed.): Los comerciantes limeños a fines del siglo XVIII. Capacidad y cohesión de una elite. 1750- 1825. Lima: Pontificia Universidad Católica del Perú, pp. 133-173.

Wuffarden, Luis (2006): "Avatares del bello ideal. Modernismo clasicista versus tradiciones barrocas en Lima, 1750-1825”. En: Mújica, Ramón (ed.): Visión y símbolos: del virreinato criollo a la República Peruana. Lima: Banco de Crédito del Perú, pp. 113-160. 


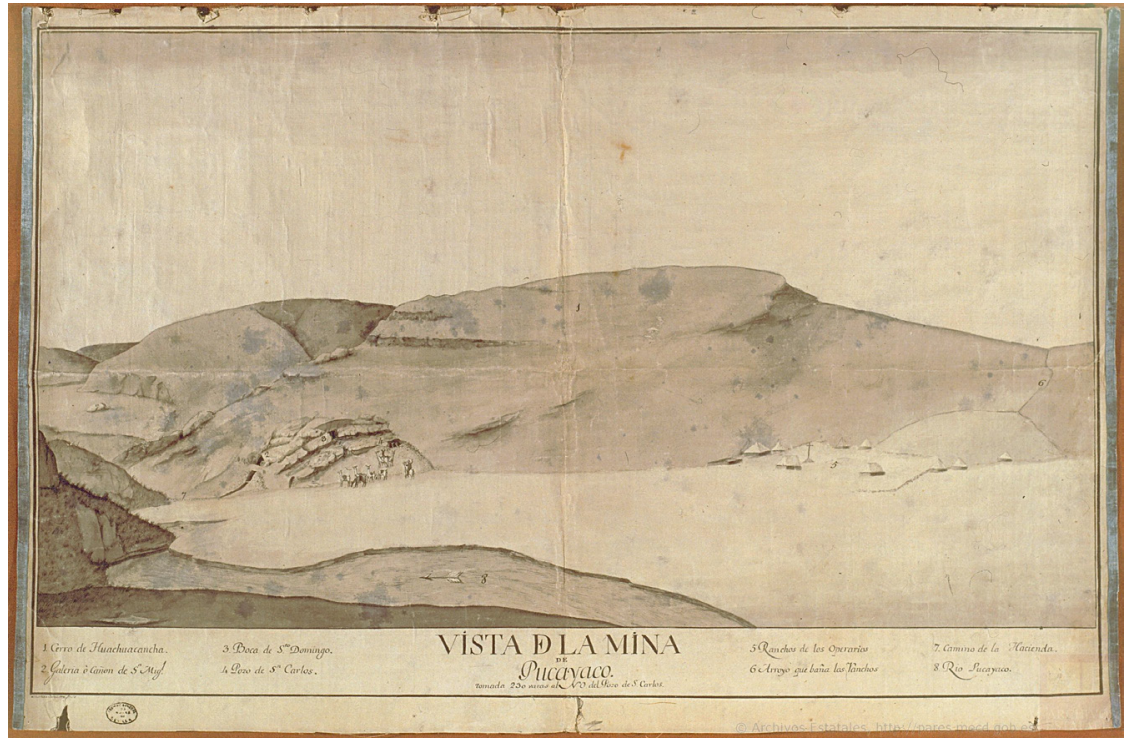

Figura 1. Matías Maestro, Vista de la mina de Pucayaco tomada 230 varas al norte del pozo San Carlos, 1789, dibujo a dos tintas sobre papel, $44,5 \times 68 \mathrm{~cm}$, Archivo General de Indias de Sevilla, ES.41091.AGI//MP-PERU_CHILE,2.

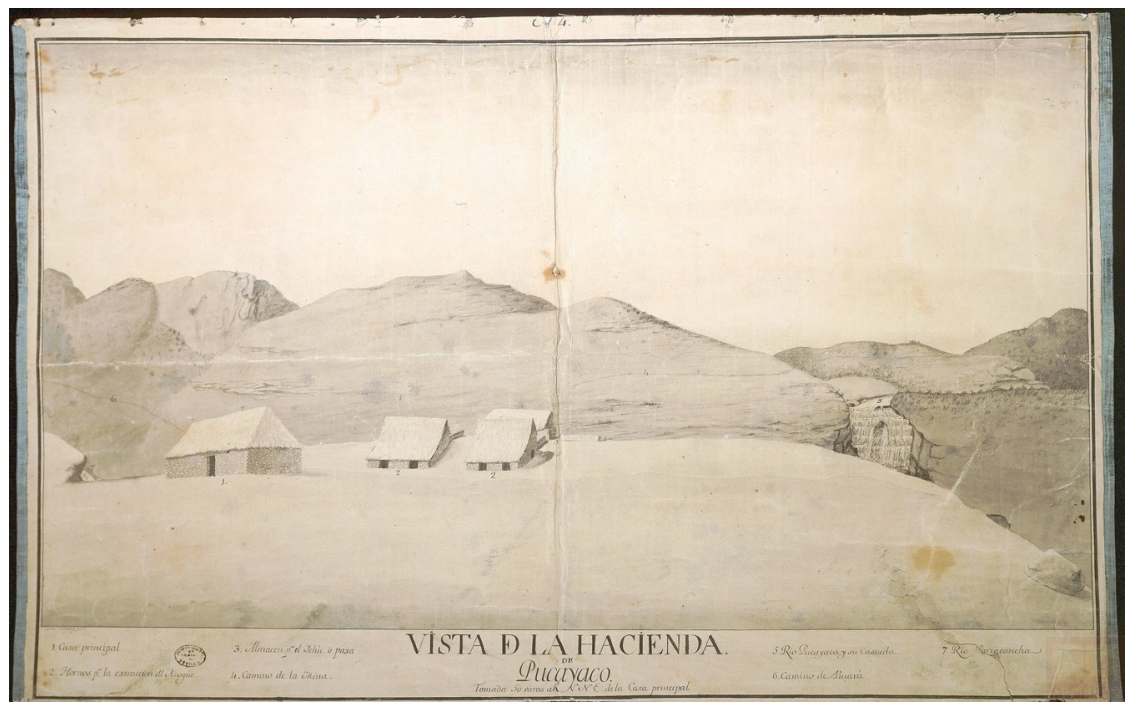

Figura 2. Matías Maestro, Vista de la hacienda de Pucayaco tomada 50 varas al noreste de la casa principal, 1789, dibujo a dos tintas sobre papel, 40,8 x 65,5 cm, Archivo General de Indias de Sevilla, ES.41091.AGI//MP-PERU_CHILE,3. 